\title{
Women's perception about accessibility of safe abortion care services at selected public institutions in Addis Ababa, Ethiopia.
}

\section{Endalew Gemechu Sendo}

Addis Ababa University

Negalign Getahun Dinegde ( $\nabla$ negalign999@gmail.com )

Addis Ababa University https://orcid.org/0000-0001-6338-4222

Fekadu Aga

Addis Ababa University

Debela Gela Negassa

Addis Ababa University

Jembere Tesfaye Deressa

Addis Ababa University

Research article

Keywords: Women, Perception, Safe abortion, Accessibility, Addis Ababa, Ethiopia

Posted Date: October 9th, 2019

DOI: https://doi.org/10.21203/rs.2.15781/v1

License: (c) (1) This work is licensed under a Creative Commons Attribution 4.0 International License.

Read Full License 


\section{Abstract}

Background Ethiopia ratified its abortion law in 2005, primarily to reduce the incidence of unsafe abortion and the availability of safe abortion services has increased. However, service availability has not led to a significant reduction in unsafe abortion.

Objective The aim of this study was to assess women's perception about accessibility of safe abortion care services at selected public institutions in Addis Ababa, Ethiopia.

Method Institution-based cross-sectional study was conducted among 432 women of reproductive age who work in non-health related public institutions. A structured questionnaire was used to collect the data. Data were entered into Epi-data and cleaned and exported to SPSS version 24.0 for data analysis. Data analysis involved descriptive statistics, independent-sample t-test, one-way analysis of variance (ANOVA), and linear regression. Statistical significance was set at $5 \%$. Multi-categorical independent variables were dummy coded before entering into the models.

Results In this study, more than half (60.2\%) of the participants reported that they had pregnancy at least once. Seventy eight respondents (18.1\%) had history of previous miscarriage, among these the greater number $(74.4 \%)$ has happened due to spontaneous abortion. Among the respondents studied, 283 (65.5\%) of them have heard of abortion care and media was the major source of information. Closely half of $(46.2 \%)$ the females who had miscarriage history were treated at governmental health institutions; followed by private clinics (35.9\%) and traditional methods (6.4\%). Whereas, $11.5 \%$ of them didn't get any abortion care service. There was significant difference in mean scores of participants faced post abortion complications and treated at traditional healer, and particularly the respondents attended traditional healer makes the strongest unique contribution to explaining the perception score.

Conclusion Over the past two decades, the safe abortion services has advanced and expanded increasingly in Ethiopia. However, this study indicated that significant number of women still unheard about accessibility of the safe abortion care and attending the traditional and risky procedure of care. There is an urgent need for the government and other stakeholders to provide more awareness on the accessibility and advantage of safe abortion services in the community.

\section{Introduction}

- Background to the Study

Abortion is the termination of pregnancy before foetal viability, which is conventionally taken to be less than 28 weeks from the last normal menstrual period (LNMP). If the LNMP is not known, a birth weight of less than $1000 \mathrm{gm}$ is considered as abortion[1]. Unsafe abortion is defined by the World Health Organization (WHO) as a procedure for terminating an unintended pregnancy, carried out either by persons lacking the necessary skills or in an environment that does not conform to minimal medical standards, or both [2]. Unsafe abortions are frequently performed by providers lacking qualifications and 
skills to perform induced abortion, and some abortions are self-induced. Unsafe abortion remains a leading cause of maternal mortality and morbidity in Africa, including Ethiopia [3]. The WHO [4] estimates that an annual 22 million unsafe abortions occur globally, almost all of which take place in developing countries, and account for $13 \%$ of all maternal deaths [3]. Complications from unsafe abortion result in maternal deaths and abortion-related morbidities worldwide, placing high strain on limited health system resources and leading to severe physical, psychological, and financial consequences for women [5].

One in 27 women die from complications of pregnancy or childbirth [6, 7], the number of maternal deaths is fifth highest in the world [8] and the maternal mortality ratio, estimated to be 412 per 100,000 live births, is still enormously high in Ethiopia [9]. In Ethiopia $32 \%$ of all maternal death is due to unsafe abortion [1]. In addition, unsafe abortion accounts for nearly $60 \%$ of all gynaecologic admissions and almost $30 \%$ of all obstetric and gynaecologic admissions in the country $[1,10]$.

Evidence shows that the induced abortions are more likely in countries in which abortion is illegal or restricted compared to those liberated [11].Death and disability from unsafe abortion can be prevented in three ways: by preventing unintended pregnancy, treating the complications of women who seek post abortion care or providing a safe, legal alternative to unsafe abortion [7].

Cognizant of the extent of the problem of unsafe abortion, and with due recognition of the need for an integrated approach to reducing maternal morbidity and mortality, Ethiopia liberalized its abortion law in 2005 and consequently authorized midlevel health care providers to offer abortion services [1]. In most political systems, the enactment of a law alone is however no guarantee of its implementation [12].

This has been true for abortion laws in particular, because internationally legal liberalization has not reliably led to increased access to services, particularly in more traditional settings where abortion is prohibited on religious grounds $[13,14]$.

While legal reform took place in Ethiopia ten years ago, social norms about abortion are just start to change, and the expansion of safe abortion services has advanced steadily [7]. As current studies, both in and outside of Africa, recommend legal reform is not adequate to eradicate unsafe abortion. Researchers and policymakers have emphasized the need to decrease abortion stigma, inform citizens of their rights and address inequities in abortion accessibility $[1,15]$.

Access to and provision of correct information is a key determinant on the pathway to safe abortion. The absence of accurate knowledge and the fear of violating law creates a chilling effect and deter women from seeking health care services $[2,16]$. Women's own knowledge of the law is only one factor in their being able to access appropriate care. Knowledge of accessible safe abortion services, providing women with information on the legal context and methods to allow access to such information assist in decreasing the chances that a woman will seek unsafe abortion services and consequently decreasing her likelihood of suffering from abortion related morbidity or mortality [16]. Therefore, it is imperative to understand on women's perception and knowledge about accessibility of safe abortion care services. 
Unsafe abortion is a major contributor to maternal deaths (32\%) in Ethiopia [1, 17]; young and poor women suffer most from unsafe abortion, but all sub- groups of women are also at risk [17]. Increasing access to safe abortion services is the most effective way of preventing the burden of unsafe abortion, which is achieved by increasing safe choices for pregnancy termination [18].

Although Ethiopia liberalized its abortion law in 2005, service availability has not led to a significant reduction in unsafe abortion [7]. In addition to legal and policy interventions, a number of interventions to increase the availability of safe abortion services have been implemented in Ethiopia $[1,19]$. For instance, there has been a rapid expansion of health facilities eligible to provide legal abortion services in Ethiopia since 2008. Comprehensive abortion services also increased from $20 \%$ of the recommended level in 2008 to $38 \%$ in 2014 [19]. Disappointingly, these policy and service delivery interventions have not led to a significant reduction in unsafe abortion [7] or related maternal mortality and morbidity in Ethiopia primarily because of limited access to and utilization of safe abortion services. The Ethiopian ministry of health has also recognised that the revision of legal policies alone might not in itself ensure the accessibility of the service if other factors were not addressed as well [1]. Available safe abortion services are underutilized due to various individual and community-level factors, such as lack of awareness of the legality of abortion, negative attitude of the providers, limited understanding on the implications of unsafe abortion and lack of information on availability of safe providers and methods [20,21]. Ensuring that all women know that safe abortion is available and legal for many indications will further reduce morbidity from unsafe abortions [7].

While there are few previous studies on safe abortion in Ethiopia and elsewhere in the world [22] there seems to be a gap on women's knowledge of and perceptions on accessing safe abortion services [16]. Therefore, this study aimed to contribute to filling this critical gap and focus on women's perception and knowledge about accessibility of safe abortion care services at selected public institutions in Addis Ababa, Ethiopia.

- Objectives

- General Objective

The objective of this study is to assess women's perception about accessibility of safe abortion care services at selected public institutions in Addis Ababa, Ethiopia.

- Specific objectives:

Assess the women's perception about accessibility of safe abortion care service

- Determine factors associated with women's perception about accessibility of safe abortion care services

\section{Methods}

- Study area 
This study was conducted in Addis Ababa, the capital city of Ethiopia. The city is subdivided into 10 subcities the second administrative layer of the city and 116 'Weredas' the smallest administrative unit of the city [23]. Based on Proclamation No 35/2012, the city has 14 Bureaus and 38 executive organs and higher education institutions re-established being legal persons [24]. From these 9 are health related offices or institutions. There are 6 public hospitals and 53 health centers run by the Addis Ababa City Government [23].

- Study design and period

An institutional based quantitative research method was conducted from April 1 to June 30, 2019

- Source of population

Women of reproductive age residing in Addis Ababa were the source population for this study.

- Study population

All reproductive age women who work in non-health related public institutions were study population of this study.

- Inclusion and exclusion criteria

\section{Inclusion criteria:}

Women with the following characteristics were included in this study:

- In a reproductive age,

- Working in one of the selected public institution of the Addis Ababa City Administration

- Willing to participant in the study.

\section{Exclusion criteria:}

Being on annual or sick leave during the data collection time and unwillingness to participate in the study was an exclusion criterion.

- Sample size determination

The sample size for this study has been calculated using online calculator for women by using $95 \%$ confidence limit, $80 \%$ power and 0.2 effect size. We have used 10,000 population variance for women's group. Accordingly, the sample size required the women's group was 393. The final sample size was 432 for women after including $10 \%$ non-response rate.

- Sampling method 
Since it was impossible to obtain the list of reproductive age women, one-stage cluster sampling of the institutions was used in order to enroll the required samples in this study. Accordingly, $30 \%$ of the Bureaus or institutions in the Addis Ababa City Government were selected using a simple random sampling method. This resulted in a cluster of 13 non-health institutions. Finally, using a proportional allocation to the size approach 432 reproductive age women were selected from the 13 non-health institutions.

- 00Data Collection procedures and methods

Data was collected using structured questionnaire adapted from other studies [25] to assess women's' perception about accessibility of safe abortion care services. The questionnaire consisted of six sociodemographic items for women, 11 reproductive health characteristics items for women, and 10 Likert scale type items to assess women's perception of the accessibility of safe abortion care. The questionnaire was translated from English to Amharic by a bilingual expert and back translated to English by another bilingual expert in order to ensure meaning equivalence between the two language versions. The Amharic version questionnaire was pretested on $5 \%$ of the study sample in institutions not selected for the parent study prior to the actual data collection. Four data collectors and 2 supervisors (voluntary health professional) were recruited from outside selected public institutions. The data collectors and supervisors were trained based on the training manual 5 work days by the principal investigator and co-investigators. An additional training on data completeness, cross-checking and correction actions was given to the supervisors.

- Operational definitions

Accessibility: Within health care, access is always, defined as access to a service, a provider or an institution, and thus defined as the opportunity or ease with which consumers or communities are able to use appropriate services in proportion to their needs [26]. In our study accessibility is defined as the opportunity for women in reproductive age to reach and obtain appropriate safe abortion care services within easy-to-reach distance, at the right health facility, by a skilled provider at an affordable price.

Perceived accessibility of safe abortion care: The Oxford Advanced Learner's Dictionary (2010:1132) defines 'perception' as a particular attitude towards something or view point. In this study, perception refers to client views on accessibility of safe abortion care services. In this study perceived accessibility of safe abortion care is defined as the woman's and health providers expressed satisfaction and attitude concerning the convenience of care, its coordination and cost, providers courtesy, information obtained, and quality of care.

Perceived accessibility of safe abortion care will be measured by a 10 -item Likert scale with 5 response options. The response options involve 'Strongly Disagree $=1$, Disagree $=2$, Neutral $=3$, Agree $=4$, and Strongly Agree $=5$.' The total score was computed for each respondent and it ranges from 10-50. A higher score indicates more favorable perception.

- Data processing and analysis procedures 
After data collection, filled questionnaires were coded, checked, cleaned and entered in to Epi data software, then imported to SPSS version 24.0 software for analysis. Incomplete and inconsistent data were excluded from the analysis. Data analysis involved descriptive statistics, including frequency, percentage, mean and standard deviations. Bivariate analysis using correlation coefficients, independentsample t-test, and one-way analysis of variance (ANOVA) were conducted to assess factors associated with knowledge and perception about accessibility of safe abortion care. Statistical significance was set at $5 \%$. Multiple linear regression analysis was used to identify variables independently predicting knowledge and perception about accessibility of safe abortion care.

Multi-categorical independent variables were dummy coded before entering into the models. To avoid issues associated with multicollinearity, we have checked to see if (a) the condition index was $<3$, (b) that the variance inflation factors $(\mathrm{VIF})$ were $<5$, and (c) tolerance was $>0.2$.

- Data quality control

To maintain data quality, all data collectors were health professionals and all of them were trained on data collection procedures by principal investigator and co-investigators. Moreover, the data collection instrument and procedures were pretested on $5 \%$ of the study sample in the institutions not selected for parent study to see the accuracy of responses, language clarity, appropriateness of data collection tools, estimate the time required and the necessary amendments were considered.

\section{- Ethical consideration}

An ethical approval was obtained from Institutional Review Board (IRB) of the College of Health Sciences at Addis Ababa University. Letter of permission was obtained from Addis Ababa Health Bureau which also provided us letter of cooperation written to all selected public institutions. Following an explanation

of the purpose of the study informed consent was obtained from those who met the inclusion criteria and agreed to participate. Also information regarding their unconditional right to withdraw consent and discontinue participation without any form of prejudices was provided. Confidentiality of information and privacy of participants has been maintained for all the information provided, to preserve the confidentiality the data has been kept in a locked cupboard and not accessible by any other person except the principal and co-investigators.

\section{Results}

- Socio-demographic characteristics

A total of 432 women participated in this study with $100.0 \%$ of response rate. More than half $(55.8 \%)$ of the respondents were married and majority (81.5\%) of them were orthodox Christian. The age of study participants ranged from 18 to 48 years, with an average age of 28.5. The distribution by biosocial characteristics of the respondents is shown in Table 1. 
Table 1: Socio-demographic characteristics of women's perception and knowledge about accessibility of safe abortion care services at selected public institutions in Addis Ababa, Ethiopia 2019.

\begin{tabular}{lll}
\hline Variable & Number & Percent \\
\hline Mean age(Range; SD) & $29.51(18-48 ; 5.4)$ \\
Marital status & & \\
$\quad$ Single & 163 & 37.7 \\
$\quad$ Married & 241 & 55.8 \\
$\quad$ Other & 28 & 6.5 \\
\hline Educational status & & \\
$\quad$ Pre-university school & 85 & 20.0 \\
Diploma & 166 & 39.0 \\
Degree and above & 175 & 41.1 \\
\hline Religion & & 81.5 \\
Orthodox & 352 & 13.9 \\
Protestant & 60 & 4.6 \\
Others** & 20 & 79.9 \\
Place grew up & & 20.1 \\
$\quad$ Urban & 345 & \\
$\quad$ Rural & 87 & $*$ Muslim, Catholic etc. \\
\hline *widowed and divorced & & \\
\hline
\end{tabular}

- Reproductive health characteristics and exposure to abortion information

In this study, more than half $260(60.2 \%)$ of the participants reported that they had pregnancy at least once; among which majority were primigravid $102(39.2 \%)$ and have given birth to baby once $110(42.3 \%)$ (Figure: 1). Seventy eight (18.1\%) respondents had history of previous miscarriage, among these the majority $(74.4 \%)$ has happened due to spontaneous abortion.

Figure 1: Status of gravidity and parity of women at selected public institutions in Addis Ababa, Ethiopia 2019.

Among the respondents studied, $283(65.5 \%)$ of them have heard of abortion care and media was the major source of information (79.5\%), while peers, books, internet, and others accounted for $23 \%, 21.6 \%$, $9.9 \%$ and $1.8 \%$ respectively. Regarding abortion care provision for women who had history of miscarriage, nearly half of them (46.2\%) treated at governmental health institutions; followed by private clinics (35.9\%) and traditional methods (6.4\%). Moreover, $11.5 \%$ of them didn't get any abortion care service. 
Concerning complications after the abortion, majority of the participants (74.4\%) didn't face any complication. Among the $20(25.6 \%)$ of women who suffered the post abortion complication, the majority $15(75 \%)$ mentioned that they encountered hemorrhage (figure 2 ).

Figure 2: Depicts abortion complication types faced by women at selected public

Institutions in Addis Ababa, Ethiopia 2019.

- Factors affecting women's perceptions towards abortion care service provision

Table 3 shows an independent-samples t-test conducted to compare the perception scores among dichotomous independent variables. There was significant difference in scores for participants faced post abortion complications $(M=52.2, S D=6.54)$ and didn't face complications $(M=53.5, S D=6.05$; $t$ $(54)=2.12, p=0.39$, two-tailed). In addition, there was significant difference in scores for participants treated at traditional healer $(M=62.8, S D=3.42)$ and those didn't $(M=54.93, S D=6.5 ; t(73)=2.7, p=$ 0.009 , two-tailed). The magnitude of the differences in the means (mean difference $=.00,95 \% \mathrm{Cl}: 2.01$ to 13.73) was very small.

In this study, the analysis of variance (ANOVA) showed that the effect of education, marital status and religion was not significant: $F(2,423)=1.86, p=0.16 ; F(2,429)=1.36, p=0.26$ and $F(2,429)=0.85, p=$ 0.43 respectively.

Table 3: Factors influencing the perception of women at selected public institutions in Addis Ababa, Ethiopia 2019.

\begin{tabular}{|c|c|c|c|c|}
\hline Variable & & $\mathbf{N} \%$ & $\mathrm{t}$ & $P$ value \\
\hline \multirow[t]{2}{*}{ Place of grew up } & Urban & 79.9 & 1.71 & 0.089 \\
\hline & Rural & 20.1 & & \\
\hline \multirow[t]{2}{*}{ Pregnancy } & Yes & 60.2 & 0.96 & 0.34 \\
\hline & No & 39.8 & & \\
\hline \multirow{2}{*}{ Treated at traditional healer } & Yes & 1.2 & 2.68 & 0.009 \\
\hline & No & 98.8 & & \\
\hline \multirow[t]{2}{*}{ Previous abortion information } & Yes & 65.5 & 0.9 & 0.37 \\
\hline & No & 34.5 & & \\
\hline \multirow[t]{2}{*}{ Abortion complications } & Yes & 4.62 & 2.12 & 0.039 \\
\hline & No & 95.38 & & \\
\hline
\end{tabular}

Moreover, the univariate linear regression model indicated that there is significant differences in the perception score with the participants' level of knowledge. The size of the estimated regression coefficient suggests that for one additional knowledge mark, the respondents' perception also increases by 0.5 
score. The models did not show any significant differences in the score with marital status, number of deliveries and religion.

- The factors influencing women's perception about accessibility of safe abortion care services

In addition, multiple linear regressions were used to assess the effect of a number of factors to predict levels of perception. After the variance explained by all other variables in the model is controlled, the respondents those attended traditional healer makes the strongest unique contribution to explaining the perception score recording a standardized beta value of 0.328 . As shown in the table; the knowledge on abortion and women who attended traditional healer is making a significant unique contribution to the prediction of the perception level.

Table 5: The factors influencing women's perception about accessibility of safe abortion

Care services at selected public institutions in Addis Ababa, Ethiopia 2019.

\begin{tabular}{|c|c|c|c|c|c|c|}
\hline \multirow[t]{2}{*}{ Variable } & \multirow[t]{2}{*}{$\begin{array}{c}\text { Beta } \\
\text { (stand') }\end{array}$} & \multirow[t]{2}{*}{$\begin{array}{l}\mathrm{P} \\
\text { Value }\end{array}$} & \multicolumn{2}{|c|}{$\begin{array}{c}\text { Confidence } \\
\text { interval }\end{array}$} & \multicolumn{2}{|c|}{$\begin{array}{l}\text { Collinearity } \\
\text { statistics }\end{array}$} \\
\hline & & & Lower & Upper & Tolerance & VIF \\
\hline Age & -0.104 & 0.474 & -0.442 & 0.208 & 0.616 & 1.622 \\
\hline Number of pregnancy & 0.137 & 0.544 & -1.711 & 3.219 & 0.254 & 3.941 \\
\hline Number of delivery & -0.004 & 0.986 & -2.887 & 2.837 & 0.276 & 3.621 \\
\hline Knowledge on abortion & 0.233 & 0.049 & 0.002 & 0.995 & 0.948 & 1.055 \\
\hline $\begin{array}{l}\text { Attended traditional } \\
\text { healer }\end{array}$ & -0.328 & 0.007 & -13.609 & -2.187 & 0.911 & 1.098 \\
\hline Place of grew up & 0.114 & 0.333 & -1.803 & 5.242 & 0.936 & 1.068 \\
\hline Pregnancy history & 0.042 & 0.740 & -2.615 & 3.660 & 0.792 & 1.262 \\
\hline
\end{tabular}

\section{Discussion}

The aim of this study was to develop an evidence base to realize concerns related to the perception of accessibility of safe abortion services in Addis Ababa from the perspective of public servant women. The researchers discussed findings about women's socio-demographic characteristics, information exposure, reproductive history, place of abortion care seeking, and perceptions. The findings have implications for the promotion of safe abortion service and reduction of unsafe abortion which is one of the leading cause of maternal morbidity and mortality in Ethiopia.

In this study, one fifth of the participants had history of previous miscarriage and it has happened predominantly due to spontaneous abortion. The study is in contrast to a study done in southern Ethiopia which showed that virtually all of the abortions were induced and the reason may relies in the study population, which was among tertiary education students $[27,28]$. In addition, another study done in rural southern Ethiopia revealed high level of induced abortion, and the discrepancy was probably due to the 
study setting where modern family planning is less spread and as a result consequences unwanted pregnancy [29]. Furthermore, it is not in agreement with a study done in Cambodia whish shown that induced abortion was widely used [30] and the reason could be the study population as the study participants were women sex workers which might rise chance of the unwanted pregnancy.

Among the respondents studied, two third of the women have heard of safe abortion care and media was the major source of information. This in an agreement with the study done in South Africa which indicated that radio and television as their main source of information and little has been done to promote safe abortion service through health care providers and other means of communications [31]. In contrast a study conducted in India showed that the respondents had limited exposure to mass media [32]. This could be on account of most of the participants in the Indian research had never attended school.

Although access to basic abortion care services in Ethiopia exceeded the recommended level of facilities providing the service [33], the current study showed that about $46.2 \%$ of the women stated that they attended governmental health institutions to get abortion care service; while the others went to private clinics $(35.9 \%)$, traditional procedures $(6.4 \%)$, and $11.5 \%$ of them didn't get any abortion care service. This is in parallel with the studies done in Kenya which showed that abortion services outside public health facilities were mentioned frequently $[34,35]$. Probably the reasons are the need for confidentiality to escape condemnation, hesitation about the law, and perceived expensive safer abortion services.

WHO reported that abortion performed by qualified persons using correct techniques and in sanitary conditions is safe and seldom presents complications [36]. In present study, when asked about complications after abortion, three fourth of the women reported that they didn't face any complication. This could be as a result of large number of the respondents reported spontaneous abortion which proceeds rare fatality and infrequently acquires complications. However, the study revealed that hemorrhage was the commonly reported type among the women who suffered the post abortion complication.

After the variance explained by all other variables in the model is controlled, the respondents those attended unhygienic procedure makes the strongest unique contribution to explaining the perception score. Moreover, the knowledge on abortion is making a significant unique contribution to the prediction of the perception level. This is in line with the study conducted in Ihar and Jharkhand, India [32]. Dissimilarity, the study conducted in western Kenya indicated that the health care provider, the social, economic and cultural norms influenced perception of women's access to safe abortion services [34].

\section{Conclusions}

Ethiopian federal ministry of health declared and implemented policies and guidelines about access to women centred services that are provided by trained and competent professionals with up-to-date technologies and that are easy-to-reach, inexpensive, and unbiased over the past decade in order to reduce the magnitude of unsafe abortion complications and deaths. However, this study indicated that 
significant number of women still unheard about accessibility of the safe abortion care and attending the untrained personnel services and risky procedure of care. There is an urgent need for the government and other stakeholders to provide more awareness on the accessibility and advantage of safe abortion services in the community.

\section{Abbreviations}

ANOVA: one-way analysis of variance

IRB: Institutional Review Board

LNMP: the last normal menstrual period

REC: Research Ethics Committee

VIF: variance inflation factors

WHO: World Health Organization

\section{Declarations}

Ethics approval and consent to participate: Ethical clearance was obtained from Research Ethics Committee (REC) of Addis Ababa University, college of Health science. Permission from Addis Ababa city municipality, and then informed written consent of individual participants was obtained after being fully informed of the study purpose and procedures. During the consent process, they were provided with information regarding the purpose of the study, why and how they selected for this study and opportunity given to ask questions if they had. Participants also assured about confidentiality of the information obtained from them during the data collection by not using personal identifiers and analysing the data in aggregates. Confidentiality and anonymity was ensured. No name or other identifying information included in the instrument.

Consent for publication: Not applicable

Availability of data and material: The datasets used and/or analysed during the current study are available from the corresponding author on reasonable request.

Competing interests: The authors declare no conflict of interest, financial or otherwise.

\section{Acknowledgements}

Addis Ababa University, college of health science.

Centre for International Reproductive Health Training-Ethiopia. 


\section{References}

1.FMOH: Technical and Procedural Guidelines for Safe Abortion Services in Ethiopia. Addis Ababa: Federal Ministry of Health Ethiopia.. In.; 2006.

2.Musembi J: Determinants of Adherence to Cotrimoxazole Preventive Therapy among HIV Infected Persons on Treatment in Machakos District Hospital, Machakos County, Kenya. 2014.

3.WHO: Unsafe abortion: global and regional estimates of incidence of unsafe abortion and associated mortality in 2003. Geneva: World Health Organisation;. In.;2007.

4.Organization WH: Unsafe abortion: global and regional estimates of the incidence of unsafe abortion and associated mortality in 2008, 3rd edition. Geneva: (http://www.who. int/reproductivehealth/publications/unsafe_abortion/9789241501118/en,(accessed June 20,2017) In.; 2011.

5.Assefa Y, Kiflie A, Tesfaye D, Mariam DH, Kloos H, Edwin W, Laga M, Van Damme W: Outcomes of antiretroviral treatment program in Ethiopia: retention of patients in care is a major challenge and varies across health facilities. BMC health services research 2011, 11(1):81-81.

6.Population Reference Bureau (PRB), 2008 World Population Data Sheet,Washington, DC: PRB,. In.; 2008.

7.Gebreselassie H, Fetters T, Signh S, Abdella A, Gebrehiwot Y, Tesfaye S, Geressu T, Kumbi S: Caring for women for abortion complications in Ethiopia: National estimates and future implications. International Perspective of Sexual and Reproductive Health 2010, 36(1):6-15.

8.WHO, Maternal Mortality in 2005: Estimates Developed by WHO, UNICEF, UNFPA and theWorld Bank, Geneva: WHO,. 2005.

9.Ethiopian Central Statistical Agency and ORC Macro, Ethiopia Demographic and Health Survey: Key Indicators 2016, Addis Ababa, Ethiopia: Central Statistical Agency; and Calverton, MD, USA: ORC Macro,. In.;2016.

10.Singh S: Hospital admissions resulting from unsafe abortion: estimates from 13 developing countries.. Lancet 2006, 368(9550):1887-1892.

11.Sedgh G, Singh S, Shah I, Ahman E, Henshaw S, Bankole A: Induced abortion: incidence and trends worldwide from 1995 to 2008. Lancet.. 2012, 379(9816):625-632.

12.Patashnik E: "After the public interest prevails: The political sustainability of policy reform," Governance 2003, 16(2):203-234. 
13.Benson, Janie, Kathryn A, Ghazaleh S: Reductions in abortion-related mortality following policy reform: Evidence from Romania, South Africa and Bangladesh. Reproductive Health 2011, 8(39):1-12.

14.Singh, Susheela, Gilda S, Akinrinola B, Rubina H, London S: Making abortion services accessible in the wake of legal reforms: A framework and six case studies. New York: Guttmacher Institute. www. guttmacher.org/pubs/abortion-services-laws.pdf. In: Guttmacher Institute. 2012.

15.Gebresilase H, Fetters T, Singh S, Abdella A, Gebrehiwot Y, Tesfay S, Geresu TK, S.: Caring for women with abortion complications in Ethiopia: national estimates and future implications. Guttmacher Institute 2008.

16.Assifi A, Berger B, Tunçalp, Khosla O, Ganatra B: Women's Awareness and Knowledge of Abortion Laws: A Systematic Review. PLOS one 2016, 11(3).

17.Singh S, Wulf D, Hussain R, Bankole A, Sedgh G: Abortion Worldwide: A Decade of Uneven Progress. Yew York. Guttmacher Institute. In.;2009.

18.Woldetsadik M, Sendekie TY, White MT, Zegeye DT: Client preferences and acceptability for medical abortion and MVA as early pregnancy termination method in northwest Ethiopia. Reprod Health 2011, 8:19.

19.Dibaba Y, Dijkerman S, Fetters T, Moore A, Gebreselassie H, Gebrehiwot Y, Benson J: A decade of progress providing safe abortion services in Ethiopia: results of national assessments in 2008 and 2014. DOI 10.1186/s12884-017-1266-z. Pregnancy \& Childbirth 2014, 17(76).

20.Banerjee SK, Andersen KL, Buchanan RM, Warvadekar J: Woman-centered research on access to safe abortion services and implications for behavioral change communication interventions: a cross-sectional study of women in Bihar and Jharkhand, India. BMC public health 2012, 12(1).

21.Ganatra B, Banerjee SK: Expanding Community-Based Access to Medical Abortion in Jharkhaand: a Pre-intervention Baseline Survey in Selected Two Blocks of Ranchi and Khunti districts New Delhi:. Ipas India 2010.

22.Loi UR, Gemzell-Danielsson K, Faxelid E, Klingberg-Allvin M: Health care providers' perceptions of and attitudes towards induced abortions in sub-Saharan Africa and Southeast Asia: a systematic literature review of qualitative and quantitative data. BMC Public Health 2015, 15.

23.City_Government_of_Addis_Ababa: Socio-economic profile of Addis Ababa for the year 2004 E. C./2011/12 G. C. In. Addis Ababa: Policy Study and Analysis Sub Process; 2013.

24.Dameksa K: "Addis Ababa City Government Executive and Municipal Service Organs Re-establisment Proclamation N 35/2012". In.: Addis Negarit Gazeta No 35; 2012. 
25.Low WY, Tong WT, Gunasegaran V: Issues of safe abortions in Malaysia: reproductive rights and choice. In: Malaysia University. 2013.

26.Daniels N: Equity of Access to health care: some conceptual and ethical issues. Milbank Mem Fund $Q$ $1982,60: 51-81$.

27.Gelaye AA, Taye KN, Mekonen T: Magnitude and risk factors of abortion among regular female students in Wolaita Sodo University, Ethiopia. BMC women's health 2014, 14(1):50.

28.Mitiku1 S, PMD, FB, Mengistu Meskele4, 1. Healing hands of joy HE: Prevalence of Induced Abortion and Associated Factors among Wachamo University Regular Female Students, Southern Ethiopia. 2015.

29.Gezahegn Tesfaye MTH, 1 Agumasie Semahegn2: Induced Abortion and Associated Factors in Health Facilities of Guraghe Zone, Southern Ethiopia. 2014.

30.Delvaux T, Crabbe F, Seng S, Laga M: The need for family planning and safe abortion services among women sex workers seeking STI care in Cambodia. Reproductive health matters 2003, 11(21):88-95.

31.Varkey SJ: Abortion services in South Africa: available yet not accessible to all. International Family Planning Perspectives 2000, 26(2):87-88.

32.Banerjee SK, Andersen KL, Buchanan RM, Warvadekar J: Woman-centered research on access to safe abortion services and implications for behavioral change communication interventions: a cross-sectional study of women in Bihar and Jharkhand, India. BMC public health 2012, 12(1):175.

33.Dibaba Y, Dijkerman S, Fetters T, Moore A, Gebreselassie H, Gebrehiwot Y, Benson J: A decade of progress providing safe abortion services in Ethiopia: results of national assessments in 2008 and 2014. BMC pregnancy and childbirth 2017, 17(1):76.

34.Marlow HM, Wamugi S, Yegon E, Fetters T, Wanaswa L, Msipa-Ndebele S: Women's perceptions about abortion in their communities: perspectives from western Kenya. Reproductive Health Matters 2014, 22(43):149-158.

35.Jayaweera RT, * FMN, KSH, CG: Women's experiences with unplanned pregnancy and abortion in Kenya: A qualitative study. 2017.

36.Unsafe abortion: global and regional estimates of incidence of unsafe abortion and associated mortality in 2003

[https://www.who.int/reproductivehealth/publications/unsafe_abortion/9789241596121/en/]

\section{Figures}




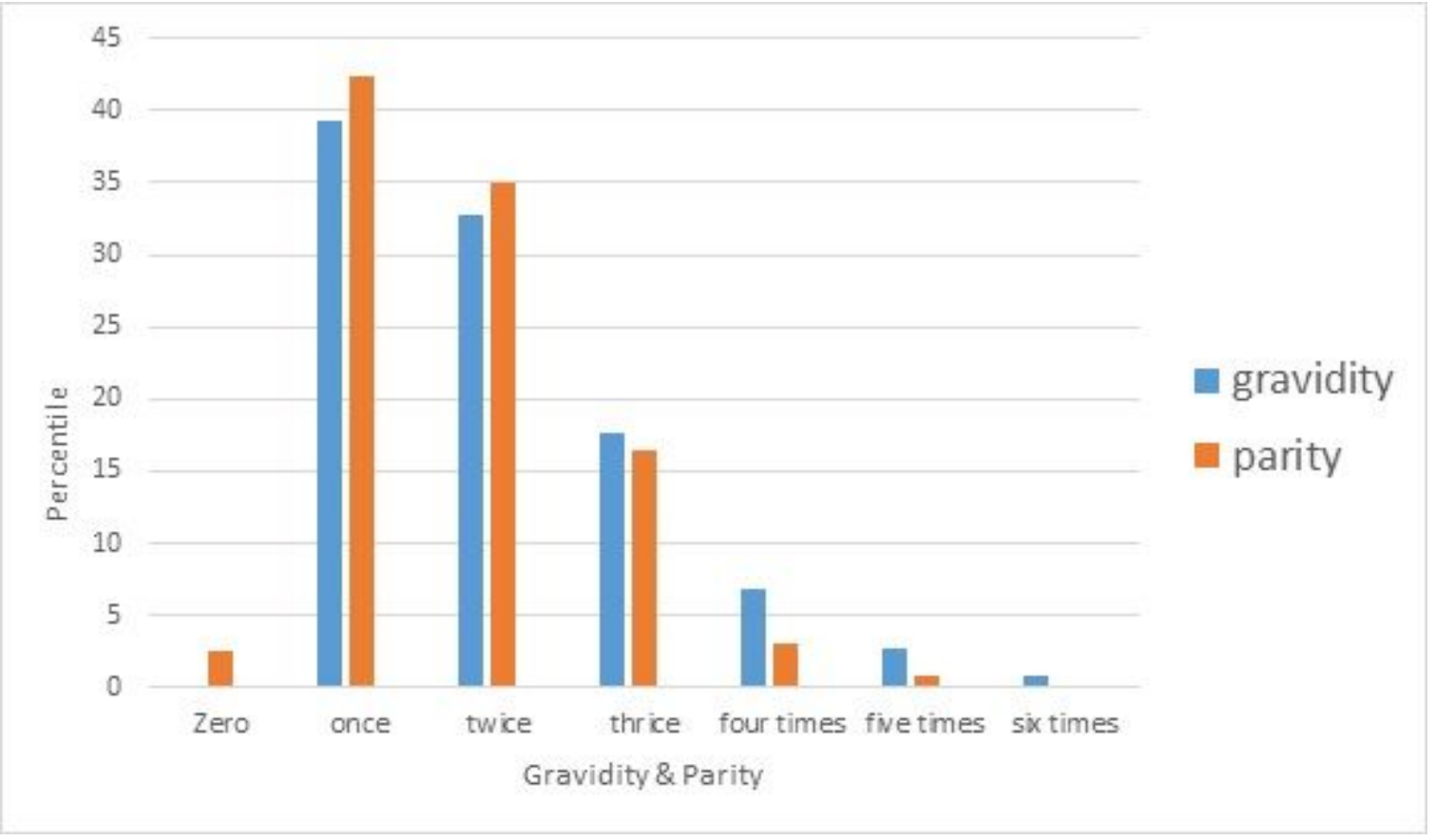

\section{Figure 1}

Status of gravidity and parity of women at selected public institutions in Addis Ababa, Ethiopia 2019.

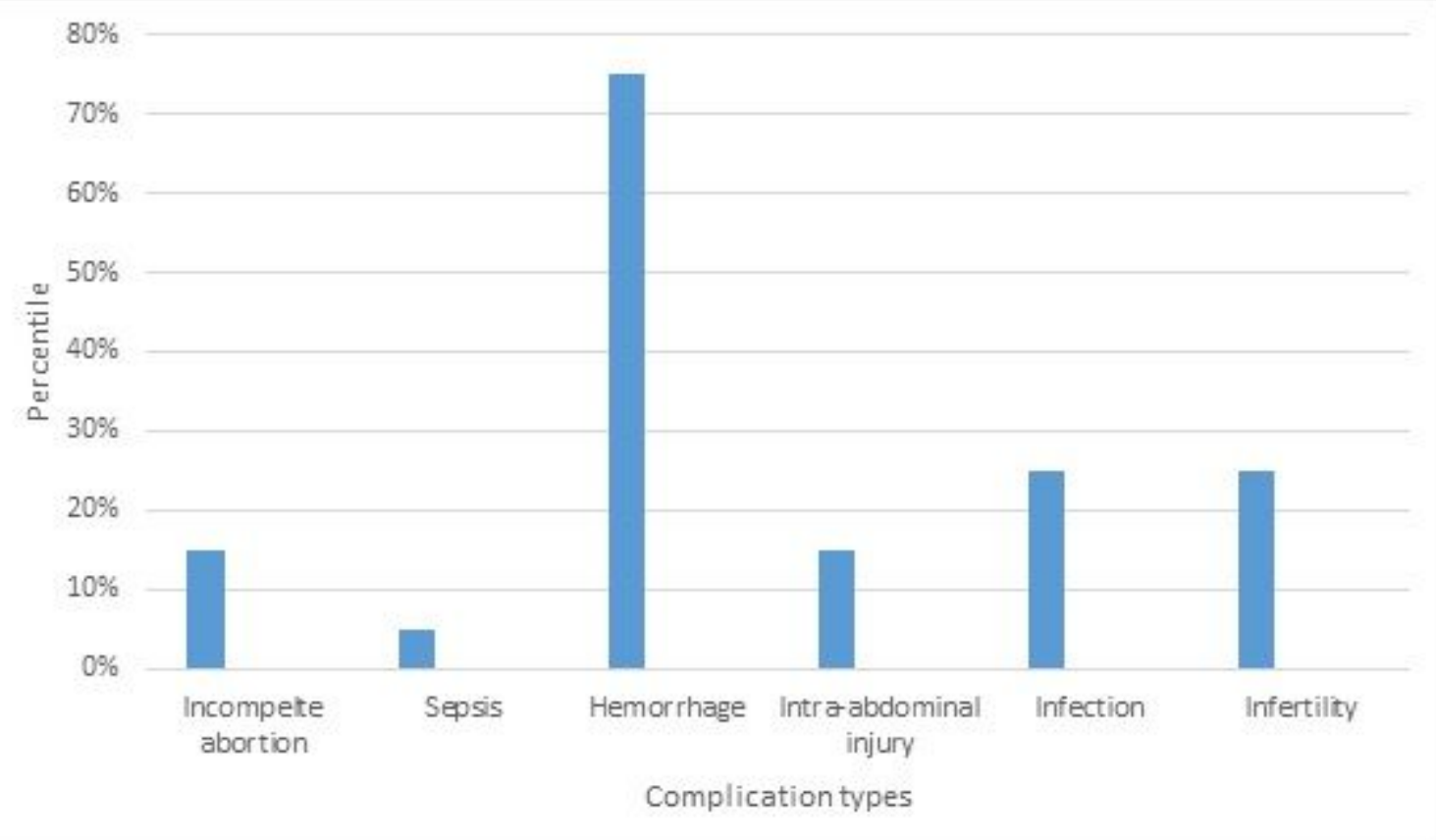

Figure 2

Depicts abortion complication types faced by women at selected public Institutions in Addis Ababa, Ethiopia 2019. 